\title{
Developmental effects of blocked vs. random input of taxonomically related words in a false recognition paradigm
}

\author{
GAIL ROSENBERG \\ Fircrest School, Seattle, Washington 98155 \\ and \\ HOWARD A. ROLLINS, JR. \\ Emory University, Atlanta, Georgia 30322
}

\begin{abstract}
Recognition memory for taxonomically related words was investigated in second- and fifthgrade children. Forty children were presented with a list of 36 words consisting of nine categories. One half of the subjects received the list in random order, the other half blocked by category. At test, each input item was accompanied by a taxonomically related and an unrelated foil. Blocking reduced the number of errors to unrelated foils for both age groups but reduced errors to related foils only for second-grade children, thus eliminating an age effect present in the random input condition. Younger children are as aware as older ones of the taxonomic structure but are less likely to remember the individual items within a category when words are presented in random order. Blocking by category increases category awareness at both ages and retention of individual items for second graders.
\end{abstract}

Manipulation of the taxonomic structure of a word list produces developmental effects on the free recall of those words. As children increase in age, particularly during the elementary school years, their recall of taxonomically structured word lists differentially increases relative to lists of unrelated words (Cole, Frankel, \& Sharp, 1971). Furthermore, blocking the words by taxonomic category at the time of presentation enhances recall performance particularly for younger children (Kobasigawa \& Middleton, 1972). In fact, one can virtually eliminate developmental effects in recall by presenting items blocked by category at input and then providing category cues at the time of recall to facilitate retrieval (Kobasigawa, 1977). Brown (1975) and Hagen, Jongeward, and Kail (1975) have suggested that these developmental effects are attributable to increasing ability with age to encode the semantic features of words, store them in terms of the taxonomic structure of the word list, and then adopt a retrieval strategy that is guided by these taxonomic categories at the time of recall. Blocking items by category at input probably increases the young child's awareness of the structure of the list, and thus makes young children more likely to encode and use that structure to guide storage and retrieval.

In contrast to recall, very little evidence is available

The data presented in this report are based upon a dissertation submitted to Emory University by the first author in partial fulfillment of the requirements for the $\mathrm{PhD}$ degree. Reprint requests should be sent to the second author, Department of Psychology, Emory University, Atlanta, Georgia 30322. on the developmental effects of taxonomic variables on recognition. If, as Hagen et al (1975) and Kintsch (1977) suggest, recognition bypasses, or makes unnecessary, any form of retrieval, then neither taxonomic variables nor age should affect recognition memory. According to such a hypothesis, the subject need only examine memory to determine whether or not each item on the recognition test has occurred recently. If, on the other hand, recognition does involve retrieval mechanisms, as suggested by Mandler (1972), then the manipulation of both taxonomic structure and age should produce effects in recognition in much the same fashion as outlined above for recall.

The purpose of the present study was to examine the developmental effects on recognition of presenting children with taxonomically structured word lists, in which the words were either randomly ordered or blocked by category at the time of presentation. In addition, a false recognition paradigm (Bach \& Underwood, 1970) was employed, in which both taxonomically related and unrelated foils accompanied the to-beremembered (TBR) item at recognition test. The latter manipulation makes it possible to determine more about the locus of any developmental and/or blocking effects. The younger children, for example, may be less aware of the taxonomic structure of the list and thus be less likely to encode the words according to taxonomic category. If this analysis were correct, young children would make fewer errors to related foils and more errors to unrelated foils than older children. Errors to related foils indicate the child's awareness that the correct item 
comes from a particular category. Choice of the related foil should be increased by blocking of the items at input, since blocking might be expected to increase awareness of the structure, particularly in young children.

It is possible that the young children do not differ from the older ones in their awareness of the taxonomic nature of the list. Rather, young children may be less likely to use taxonomic structure to facilitate retention of individual items within a category. If this analysis were correct, young children would not differ from older ones on errors to unrelated foils, but would have more difficulty with related foils. That is, young children may have difficulty deciding which of two taxonomically related items on the test is the TBR item. Blocking might increase the young child's memory for individual items within a category by increasing the likelihood that the structure is used to organize memory or to help retrieve the items from memory at test.

\section{METHOD}

\section{Subjects}

The subjects were 80 , white, middle-class children attending a suburban school whose parents signed informed consent statements. One half of the children were in the second grade (mean age 7.7 years); the other half.were in the fifth grade (mean age 10.7 years). An equal number of females and males were in each condition.

\section{Stimulus Materials}

Word lists consisted of 36 words from nine taxonomic categories. Category size was varied by including three categories in the list each with two, four, and six items per category. Four such lists were created by selecting randomly from a pool of the 18 most frequently mentioned items in each of 12 categories, as determined by a pilot study with grade-school children (Rosenberg, Note 1). For the random input condition, five different random orders of each of these four lists were created (20 lists, total), with the restriction that no two items from a given category occur together. For the blocked condition, all members of a category occurred contiguously, but order within each category was randomized five times per list to create a total of 20 lists.

For the recognition test, each TBR word was accompanied by two foils in a forced-choice procedure. The related foil was taken from the same category as the TBR item. The unrelated foil was selected from categories of the pilot study not represented in the input list and from the 10 most frequently reported items for 26 categories of the Battig and Montague (1969) norms. The order of occurrence of test trials was random for both input conditions, with no more than two triads testing a single category adjacent to each other. The TBR item and its foils were presented successively and equally often in each of the six possible orders.

\section{Procedure}

Each child was run individually in a small room provided by the school. After an initial conversation designed to develop rapport between the female experimenter (first author) and the child, each child was presented with a short practice list to demonstrate the nature of the presentation and test and was informed of the categories on his/her particular list. The 36-item list was then read aloud to the child at a 2 -word/sec rate. Immediately following the last TBR item, the test list was presented by reading aloud at a 2 -word/sec rate, each triad consisting of a TBR item and two foils. Subjects chose which one of the three items occurred at input by naming that item aloud. The experimenter would repeat the triad of list words one time at the child's request.

\section{RESULTS}

The mean proportion of errors to related and unrelated foils is presented in Table 1 by grade and condition. A five-way analysis of variance was run with grade, condition, and sex as between-groups factors and error type and items per category as within-groups factors. As can be seen in Table 1, fifth-grade children made fewer errors than second-grade children $[F(1,72)=5.63$, $\mathrm{p}<.05, \mathrm{MSe}=.018]$. There were fewer errors made in the blocked input order than the random order $[\mathrm{F}(1,72)=5.23, \mathrm{p}<.05, \mathrm{MSe}=.018]$. More related errors were made than unrelated ones $[\mathrm{F}(1,72)=46.09$, $\mathrm{p}<.05, \mathrm{MSe}=.008]$. Finally, both the Condition by Error Type $[F(1,72)=7.13, p<.05]$ and the Grade by Condition by Error Type $[F(1,72)=5.61, p<.05]$ interactions were significant.

An analysis of the simple interaction effects of grade and condition for each error type within the significant triple interaction indicated that blocked presentation produced fewer unrelated errors than did random input for both grades $[F(1,72)=19.04, p<.05]$.

For related errors, there was an effect of grade $[F(1,72)=15.26, p<.05]$ and an interaction of grade and condition $[F(1,72)=6.13, p<.05]$. Secondgrade children made more related errors than fifthgrade children only in the random input condition $[F(1,72)=20.31, p<.05]$, and second-grade children made more related errors with random input than with blocked input $[F(1,72)=4.67, p<.05]$. For fifth-grade children, blocking of input had no effect.

Finally, items per category, sex, and condition interacted $[F(2,144)=4.65, p<.05]$. This was the only effect of items per category and was a result of flat items-per-category gradients for every group but male subjects in the random input condition. The males made substantially more errors for categories with four items than for categories with two or six items.

\section{DISCUSSION}

Several conclusions are justified by the results of the present study. First, there is a small, but statistically reliable, increase in

Table 1

Mean Proportion of Errors to Related (R) and Unrelated (U) Foils as a Function of Grade and Condition

\begin{tabular}{|c|c|c|c|c|}
\hline \multirow[b]{4}{*}{ Grade } & \multicolumn{4}{|c|}{ Condition } \\
\hline & \multicolumn{2}{|c|}{ Random } & \multicolumn{2}{|c|}{ Blocked } \\
\hline & \multicolumn{2}{|c|}{ Foils } & \multicolumn{2}{|c|}{ Foils } \\
\hline & $\mathbf{R}$ & $\mathrm{U}$ & $\mathbf{R}$ & $\mathbf{U}$ \\
\hline $\begin{array}{l}2 \\
5\end{array}$ & $\begin{array}{l}.17 \\
.10\end{array}$ & $\begin{array}{l}.11 \\
.10\end{array}$ & $\begin{array}{l}.14 \\
.12\end{array}$ & $\begin{array}{l}.07 \\
.04\end{array}$ \\
\hline
\end{tabular}


recognition performance with age when taxonomically structured word lists are presented in random order. This result is not attributable to an increased awareness of the structure in the older children, since both age groups made the same error rate to unrelated foils. It appears that young children are less able, with random presentation, to use the taxonomic structure to facilitate the retention of individual items within a category.

Second, blocking items at input facilitated recognition memory in children just as it does for recall. Furthermore, the blocking variable facilitated performance in two distinct ways. First, tlocking improved memory for the taxonomic categories themselves at both grade levels. This conclusion is justified by the fact that blocking reduced the number of errors to unrelated foils equally for both grade levels. Second, blocking improved recognition memory for individual items within categories but only for second-grade children. This conclusion is warranted by a decrease in related errors produced by blocking, which occurred only at the second-grade level. In order to select between the TBR and the related foil, the child must determine which item was actually stored. Presentation of items in blocked order made that decision easier for the young children, which indicates that blocking made the individual items easier to remember.

Thus, blocking had the overall effect of making children at both ages more aware of the categorical nature of the list. Blocking had a further developmental effect of improving the young child's memory for individual items over and above its effect on memory for categories. As a result, blocking of the items by category eliminated the difference in performance between the age groups.

These findings may have theoretical significance with respect to our understanding of memorial processes in children's recognition. If we adopt the assumption that all items that receive attention are stored and that the manipulation of input variables such as blocking determines how items are stored (in organized fashion) and not whether they are stored (Tulving \& Bower, 1974), then blocking must have its effect at the time of the test, as the child attempts to retrieve information from memory. Clearly, this is the interpretation placed upon the effects of organizational variables in recall (cf. Brown, 1975). Mandler (1972) has suggested that recognition involves a retrieval component, particularly when subjects have difficulty determining whether or not an item was on the input list. Under these conditions, subjects attempt to recall the items on the presentation list and check recalled items against the items on the recognition test. A successful match leads to the appropriate alternative. If no match is found, the subject must guess among the available alternatives. The results of the present study suggest that young children have difficulty under just these circumstances. They are as likely to eliminate unrelated foils as are older children. However, when input is random and they must select between the TBR word and a related foil, young children make more errors than do older ones. It is possible that the older children are better able to initiate a retrieval strategy at this point that is guided by the categorical structure of the list. Young children may simply guess if they cannot immediately decide which item is correct and thus may not attempt a retrieval strategy at all. Or, they may attempt to retrieve items but not use the category information to guide their search. Kobasigawa (1977) has suggested that young childrer are less likely to employ such strategies when they attempt to recall taxonomically structured lists unless prompted or cued to do so. A similar process may be operating in recognition. If this were true, prompting subjects at recognition to initiate retrieval would facilitate recognition, particularly when children are given a difficult recognition memory task.

\section{REFERENCE NOTE}

1. Rosenberg, G. E. Children's category norms for verbal items in 13 categories. Unpublished manuscript, 1972. (Available from G. Rosenberg, Fircrest School, 15230 15th Avenue N.E., Seattle, Washington, 98155.)

\section{REFERENCES}

Battig, W. F., \& Montague, W. E. Category norms for verbal items in 56 categories: A replication and extension of the Connecticut category norms. Journal of Experimental Psychology Monographs, 1969, 80(Whole No. 3, Part 2).

BACH, M. J.; \& UNDERWOod, B. J. Developmental changes in memory attributes. Journal of Educational Psychology, 1970, 61, 292-296.

Brown, A. The development of memory: knowing, knowing about knowing, and knowing how to know. In H. W. Reese (Ed.), Advances in child developmental and behavior (Vol. 10). New York: Academic Press, 1975.

Cole, M., Frankel, F., \& Sharp, D. W. Development of free recall learning in children. Developmental Psychology, $1971,4,109-123$.

Hagen, J. W., Jongeward, R. H., \& KaIl, R. V. Cognitive perspectives on the development of memory. In $\mathrm{H}$. W. Reese (Ed.), Advances in Child Development and Behavior (Vol. 10). New York: Academic Press, 1975.

Kintsch, W. Memory and cognition. New York: Wiley, 1977.

KobasigawA, A. Retrieval strategies in the development of memory. In R. V. Kail \& J. W. Hagen (Eds.), Perspectives on the development of memory and cognition. Hillsdale, N.J: Lawrence Erlbaum, 1977.

Kobasigawa, A., \& Middleton, D. B. Free recall of categorized items by children at three grade levels. Child Development, 1972, 43, 1067-1072.

MANDLER, G. Organization and recognition. In E. Tulving \& W. Donaldson (Eds.), Organization of memory. New York: Academic Press, 1972.

Tulving, E., \& Bower, G. H. The logic of memory representations. In G. Bower (Ed.), Advances in learning and motivation (Vol. 7). New York: Academic Press, 1974.

(Received for publication July 24, 1978.) 